\title{
Breast cancer and depot-medroxyprogesterone acetate
}

\author{
WHO Collaborative Study of Neoplasia and Steroid Contraceptives ${ }^{1}$
}

\begin{abstract}
The preliminary results of a study of the incidence of breast cancer in relation to use of depot-medroxyprogesterone acetate (DMPA) are presented. The findings are based on data from three participating centres in Thailand, and one each in Kenya and Mexico. A relative risk for breast cancer of 0.7 was observed in women who had ever used DMPA; this was not statistically significant. Although no consistent decrease in risk with duration of use was observed, the lowest relative risk (0.5) was observed in women who had used DMPA for three or more years. These findings are based on small numbers and must be considered preliminary. However, they provide no evidence that DMPA increases the risk of breast cancer, and suggest that it may exert a protective effect, particularly in long-term users.
\end{abstract}

Although depot-medroxyprogesterone acetate (DMPA) has been used as a contraceptive in over 80 countries (1), it has not yet been approved for this purpose in the United States of America, in part because of concern that it may increase the risk of breast cancer. This concern is largely based on the development of mammary adenocarcinomas in beagle bitches that received approximately 25 times the usual human dose of DMPA (2). These findings have received detailed scrutiny by individual investigators (2) and expert advisory panels to the US Food and Drug Administration (FDA), the US Agency for International Development (AID), and the World Health Organization $(1,3)$. All have concluded that the beagle is not an appropriate model for humans and that the findings in beagles are of little or no value in assessing the risk of breast cancer in women who use DMPA. The two small but adequately controlled epidemiological studies conducted to date $(4,5)$ provide no evidence for an increased risk of breast cancer in users of DMPA, although neither study was of sufficient size to detect other than large alterations in risk, and neither assessed risk in long-term users.

To assess the influence of DMPA and other steroid contraceptives on risks of mammary, gynaecological, and hepatobiliary malignancies, a collaborative, multinational, hospital-based, case-control study is currently being conducted under the auspices of the

1 This report was prepared by David B. Thomas, Liza Noonan, and Anne Whitehead, on behalf of the collaborating investigators listed in Annex 1. All correspondence concerning this report, including requests for reprints, should be addressed to either: $\mathrm{Dr}$ David B. Thomas, Fred Hutchinson Cancer Research Center, 1124 Columbia Street, Seattle, WA 98104, USA; or Dr Susan Holck, Special Programme of Research, Development, and Research Training in Human Reproduction, World Health Organization, 1211 Geneva 27, Switzerland.
World Health Organization. This report presents preliminary findings of that study on the relationship of DMPA to breast cancer. It is based on data from three participating centres in Thailand, and one each in Kenya and Mexico. At other participating centres, the numbers of women who had used DMPA were insufficient to warrant their inclusion in these analyses.

\section{METHODS}

The background of this study and the methods used have been described previously (6). Briefly, cases are detected in each participating hospital by monitoring new admissions to wards where breast cancer is treated, and by checking outpatient clinics and pathology reports. Cases are restricted to women born after 1930 in all centres except Chiang Mai, where women born up to five years previously are also eligible because DMPA became available earlier there. In all areas, entry into the study is restricted to those who are resident in a defined geographical area served by the hospital and whose neoplasm was not initially detected at a family planning clinic, unless during an initial clinic visit.

Controls are selected from among hospitalized women admitted for conditions other than obstetric or gynaecological and thought not to be associated with use of steroid contraceptives. Like the cases, the controls must be residents of a defined area and born after 1925 or 1930 , according to the study area. Controls are not matched to individual cases but are selected from specific hospital wards listed in a 
Table 1. Number of breast cancer cases and controls excluded from analysis

\begin{tabular}{lrrrrr}
\hline & \multicolumn{2}{c}{ Cases } & & \multicolumn{2}{c}{ Controls } \\
\cline { 2 - 3 } \cline { 5 - 6 } & No. & $\%$ & & No. & $\%$ \\
\hline Total accrued & 269 & 100.0 & & 4501 & 100.0 \\
No. excluded from analysis: & & & & & \\
$\quad$ Not interviewed & 19 & 7.1 & & 249 & 5.5 \\
$\quad$ Prior history of breast cancer & 2 & 0.7 & & 2 & 0.04 \\
Used other injectable contraceptive & 2 & 0.7 & & 88 & 2.0 \\
No. included in the analysis & 246 & 91.4 & & 4162 & 92.5 \\
\hline
\end{tabular}

specified order. At the beginning of each week, all women who were admitted within the previous 48 hours to a particular ward and who meet the eligibility criteria are asked to participate. The same procedure is repeated on succeeding wards until two controls per case have been selected for the week. This procedure is continued on the following week beginning with the ward listed after the last one visited. Because this procedure initially resulted in the cases tending to be older than the controls, during the second and subsequent years of the study, on alternate weeks only women over 40 years of age were selected. Since this study considers other neoplasms in addition to those of the breast, there are more than two controls per case of breast cancer.

A standardized questionnaire is used to obtain information on the known and suspected risk factors for the neoplasms under study, as well as a complete obstetric and contraceptive history. The questionnaire was initially written in English. Spanish and Thai translations are used in Mexico and Thailand, and the results are subsequently transcribed onto the
English version. In Kenya, interviews are conducted in the local language, but the answers are recorded directly on to the English questionnaire. A calendar is incorporated into the questionnaire to aid in the establishment of dates of use of steroid contraceptives.

Attempts are made to validate selected items on the questionnaire, including use of DMPA, by review of hospital and clinic records. In Mexico, where injectable contraceptives other than DMPA are also used by appreciable numbers of women, users of an unknown type of injectable contraceptive were assumed to have used DMPA if injections had been received every three months.

All cases are provisionally diagnosed by a local pathologist. Slides from all participating centres are also sent to a single reference pathologist for review and classification according to the International Histological Classification of Tumours (7).

All data are coded and sent to a coordinating centre in Seattle where they are monitored for quality, processed, and analysed.

Table 2. Total numbers of cases and controls in each centre and numbers who had ever used DMPA

\begin{tabular}{|c|c|c|c|c|c|c|}
\hline \multirow[b]{3}{*}{ Centre } & \multicolumn{3}{|c|}{ Cases } & \multicolumn{3}{|c|}{ Controls } \\
\hline & \multirow{2}{*}{ Total } & \multicolumn{2}{|c|}{ DMPA-users } & \multirow{2}{*}{ Total } & \multicolumn{2}{|c|}{ DMPA-users } \\
\hline & & No. & $\%$ & & No. & $\%$ \\
\hline Kenya & 25 & 1 & 4.0 & 301 & 24 & 8.0 \\
\hline Mexico & 47 & 0 & 0.0 & 695 & 23 & 3.3 \\
\hline Siriraj & 74 & 4 & 5.4 & 1228 & 66 & 5.4 \\
\hline Chulalongkorn & 39 & 0 & 0.0 & 1009 & 75 & 7.4 \\
\hline Chiang Mai & 61 & 10 & 16.4 & 929 & 193 & 20.8 \\
\hline Total & 246 & 15 & 6.0 & 4162 & 381 & 9.2 \\
\hline
\end{tabular}


Table 3. Relative risks of breast cancer in relation to potentially confounding variables

\begin{tabular}{|c|c|c|c|c|c|}
\hline Variable & Level & $\begin{array}{l}\text { No. of } \\
\text { cases }\end{array}$ & $\begin{array}{l}\text { No. of } \\
\text { controls }\end{array}$ & $\begin{array}{l}\text { Relative } \\
\text { risk }^{a}\end{array}$ & $\begin{array}{l}\% \text { of controls who } \\
\text { had used DMPA }\end{array}$ \\
\hline \multirow{3}{*}{$\begin{array}{l}\text { Age at menopause } \\
\text { (years) }\end{array}$} & Premenopausal & 200 & 3511 & 1.0 & 9.7 \\
\hline & $<45$ & 18 & 315 & 0.7 & 6.3 \\
\hline & $\geqslant 45$ & 28 & 336 & 1.0 & 6.3 \\
\hline \multirow[t]{3}{*}{ Menopausal status" } & Premenopausal & 200 & 3506 & 1.0 & 9.7 \\
\hline & Artificial menopause & 9 & 143 & 0.7 & 2.8 \\
\hline & Natural menopause & 37 & 508 & 0.8 & 7.3 \\
\hline \multirow{5}{*}{$\begin{array}{l}\text { Age at first live birth } \\
\text { (years) }\end{array}$} & $<20$ & 40 & 1148 & 1.0 & 12.5 \\
\hline & $20-24$ & 81 & 1339 & 1.9 & 11.5 \\
\hline & $25-29$ & 34 & 464 & 2.4 & 9.9 \\
\hline & $\geqslant 30$ & 29 & 197 & 4.7 & 12.2 \\
\hline & Nulliparous" & 62 & 1011 & 3.8 & 1.3 \\
\hline \multirow{2}{*}{$\begin{array}{l}\text { History of benign } \\
\text { breast disease }\end{array}$} & No & 228 & 4082 & 1.0 & 9.2 \\
\hline & Yes & 18 & 80 & 3.2 & 7.5 \\
\hline \multirow{2}{*}{$\begin{array}{l}\text { Family history of } \\
\text { breast cancer }\end{array}$} & No & 242 & 4145 & 1.0 & 9.1 \\
\hline & Yes & 4 & 17 & 5.8 & 11.8 \\
\hline \multirow{3}{*}{$\begin{array}{l}\text { Age at menarche } \\
\text { (years) }\end{array}$} & $\leqslant 13$ & 56 & 990 & 1.0 & 6.5 \\
\hline & $14-15$ & 93 & 1782 & 0.9 & 8.1 \\
\hline & $>15$ & 96 & 1370 & 1.1 & 12.5 \\
\hline
\end{tabular}

a Adjusted for age and centre.

${ }^{b}$ Excluding 3 controls who had never menstruated and 2 with unknown menopausal status.

c Excluding 3 controls with unknown age at first live birth.

${ }^{d}$ Including 2 cases and 17 controls with previous pregnancy but no live birth.

e Excluding 1 case and 17 controls with unknown age at menarche and 3 controls who had never menstruated.

For this report, the unconditional logistic regression model for large strata $(8)$ was used to calculate estimates of relative risks adjusted for various potentially confounding variables. All potentially confounding variables were entered into the regression models as stratified variables.

\section{RESULTS}

This report is based on data on controls and those cases considered by the reference pathologist to have carcinoma of the breast, for whom complete data were received at the coordinating centre by 29 December 1983. Table 1 shows the cases excluded from analysis because: $(a)$ they had not been interviewed; $(b)$ they had a prior history of breast cancer; or $(c)$ they had used other injectable contraceptives. The two cases and 86 of the 88 controls who had used other injectable contraceptives were from Mexico. The proportions not included for other reasons were similar in all five centres.
Table 2 shows the numbers of cases and controls from each centre and the number who had ever used DMPA. Because both the number of controls per case and the proportion of controls that had used DMPA varied among the centres, all estimates of relative risks based on data from all five centres combined were adjusted for centre. They were also adjusted for age because cases tended to be older than controls in all centres, and DMPA use varied with age (data not shown).

The distribution of other known risk factors for breast cancer, which could be confounding variables, is shown in Table 3. Risk of breast cancer was found to be reduced in women with an early menopause and, after adjusting for age, to be lower in women with either a natural or artificial menopause than in premenopausal women. Risk increased with age at first live birth, and was elevated in nulliparous women with prior benign breast lesions and a family history of breast cancer. The expected decline in risk with age at menarche was not found. With this exception, these observations are consistent with those of other 
Table 4. Relative risks of breast cancer in relation to use of DMPA

\begin{tabular}{|c|c|c|c|c|}
\hline \multirow[b]{2}{*}{ Category of use of DMPA } & \multirow[b]{2}{*}{ No. of cases ${ }^{b}$} & \multirow[b]{2}{*}{ No. of controls" } & \multicolumn{2}{|c|}{ Relative risks ${ }^{u}$ adjusted for: } \\
\hline & & & Age and centre & Four variables ${ }^{c}$ \\
\hline Never used & 230 & 3754 & 1.0 & 1.0 \\
\hline Some use & 15 & 378 & $0.6(0.3-1.0)$ & $0.7(0.4-1.2)$ \\
\hline \multicolumn{5}{|l|}{ Months of use: } \\
\hline $1-12$ & 7 & 149 & $0.8(0.4-1.7)$ & $0.8(0.4-1.8)$ \\
\hline $13-36$ & 5 & 107 & $0.7(0.3-1.8)$ & $0.9(0.4-2.2)$ \\
\hline$>36$ & 3 & 103 & $0.4(0.1-1.2)$ & $0.5(0.2-1.5)$ \\
\hline Unknown & 0 & 19 & - & - \\
\hline \multicolumn{5}{|l|}{ Age at first use: } \\
\hline$\leqslant 30$ years & 7 & 179 & $0.8(0.3-1.7)$ & $1.0(0.4-2.3)$ \\
\hline$>30$ years & 8 & 199 & $0.5(0.2-1.1)$ & $0.5(0.3-1.1)$ \\
\hline
\end{tabular}

investigators and provide reassuring evidence for the validity of the data. As shown in the last column of Table 3, the proportion of controls that had used DMPA increased with age at menarche, and was particularly low in nulliparous women.

The relative risk of breast cancer in users of DMPA was adjusted for age, centre, use of oral contraceptives, calendar year of menarche, and for each of the variables in Table 3 . The year of menarche was included because use of DMPA was found to vary by year of menarche in both cases and controls. Only adjustment for age at birth of first child and nulliparity (as a combined variable) resulted in an estimated value appreciably different from that obtained by controlling only for age and centre.

As shown in Table 4, the age- and centre-adjusted relative risk in women who had ever used DMPA was 0.6 , and of borderline statistical significance (the upper limit of the $95 \%$ confidence interval was 1.0 ). However, adjustment also for nulliparity and age at birth of first child gave a relative risk of 0.7 with a $95 \%$ confidence interval that included 1.0.

The relative risk of breast cancer was lower in women who had used DMPA for more than 3 years than in shorter-term users although, after adjustment for nulliparity and age at birth of first child, there was no clear trend of a decrease in risk with increasing duration (Table 4). The relative risks shown are based on small numbers of users and their $95 \%$ confidence intervals all include 1.0 .
The last two rows of Table 4 show that the reduction in risk of breast cancer in users of DMPA, if any, is largely confined to women with a first exposure after 30 years of age. Relative risks in DMPA users did not vary significantly by age, year of menarche, menopausal status, family history of breast cancer, age at menarche, age at first live birth (including nulliparity), history of benign breast disease, or use of oral contraceptives. However, because of the small numbers of cases that had used DMPA, the power of this study to detect such interactions is low.

Too few women had used DMPA before the birth of their first child to allow investigation of the influence of such use on risk of breast cancer. DMPA had been used by only 13 of 1011 nulliparous controls, and by none of the 62 nulliparous cases; it was known to have been used before a first live birth by only 8 of 3148 parous controls and by 1 of 184 parous cases. Small numbers of early users similarly precluded an investigation of the influence of DMPA when first used at a relatively young age.

\section{DISCUSSION}

The preliminary findings presented in this paper clearly provide no evidence that DMPA increases the risk of breast cancer in humans. Results from one small case-control study of 30 cases (4), and one 
prospective study with 7 cases in 5003 users of DMPA (5), provided similar reassurance, with estimated values of relative risks in women who had ever used DMPA of 1.0 and 0.69 , respectively. Published results from human studies have so far provided no evidence to suggest an increased risk of breast cancer with DMPA use.

The finding of a relative risk of 0.7 in users of DMPA in this study, although not statistically significant, is compatible with the value of 0.69 observed in the above-mentioned prospective study. Further support for a protective effect is provided by two studies of progestogen administration in conjunction with estrogen therapy at menopause. A prospective study found rates of breast cancer to be lower in women who received estrogens plus cyclic progestogen (some of which was medroxyprogesterone acetate) than in women treated with estrogens only (9). In a small randomized trial, women who received oral medroxyprogesterone acetate plus an estrogen had lower rates of breast cancer than women who received a placebo (10). The finding in the present study that the reduction in risk was greatest in women who had used DMPA for the longest period of time provides additional evidence that DMPA may be protective against breast cancer.

This study, although larger than any other conducted to date, has not yet accumulated sufficient cases to provide a stable estimate of the relative risk in women who have ever used DMPA, or to allow more detailed analyses. Given the prevalence of use of DMPA in the controls, with the current number of 246 cases studied, there is a $90 \%$ chance of detecting actual relative risks of less than 0.4 or greater than 1.9 in women who have ever used DMPA. To provide sufficient data to detect smaller alterations in risk, and to allow for more refined analyses of greater power, data collection is continuing in all collaborating centres represented in this report.

\section{RÉSUMÉ}

\section{CANCER DU SEIN ET ACÉTATE DE MÉDROXYPROGESTÉRONE-RETARD}

Ce rapport présente les résultats préliminaires d'une étude cas-témoins collective multinationale effectuée en milieu hospitalier sur les relations entre l'acétate de médroxyprogestérone-retard (DMPA) et le cancer du sein. Il est basé sur l'analyse de données provenant de cinq centres participants, trois en Thailande, un au Kenya et un au Mexique.

Dans chaque hôpital participant, on dépiste les cas en surveillant les nouvelles admissions dans les salles réservées au traitement du cancer du sein et en procédant à des enquêtes sur les consultations externes et les rapports d'anatomo-pathologie. Dans tous les centres, les cas sont limités aux femmes nées après 1930, sauf à Chiang Mai où les femmes nées jusqu'à 5 ans auparavant sont également étudiées du fait que le DMPA y a été disponible plus tôt. Partout, les cas retenus en vue de cette étude se limitent aux personnes résidant dans une zone géographique précise desservie par l'hôpital et dont le néoplasme n'a pas été dépisté à l'origine dans un dispensaire de planification familiale, à moins que ce ne soit au cours de la première visite.

Pour chaque cas on choisit environ deux témoins parmi les femmes hospitalisées pour des raisons autres qu'obstétriques ou gynécologiques et normalement sans rapport avec l'utilisation de contraceptifs stérö̈diens.

Un questionnaire type permet de recueillir des renseignements sur les facteurs de risque, connus et présumés, associés aux néoplasmes étudiés ainsi que sur tous les antécédents en matière d'obstétrique et de contraception.

Les frottis de tous les centres sont envoyés à un même anatomo-pathologiste centralisateur pour examen standard et classification selon la Classification histologique inter- nationale des tumeurs. Toutes ces données sont codées puis envoyées à un centre coordinateur, à Seattle, où, après un contrôle de qualité, elles sont traitées et analysées. Dans ce rapport, on a utilisé le modèle de régression logistique inconditionnelle applicable aux strates d'effectif élevé pour calculer les risques relatifs estimatifs (corrigés pour différentes variables parasites éventuelles). Toutes ces variables ont été incorporées au modèle de régression où elles servent de base à la stratification.

Le présent rapport repose sur l'interrogatoire de 4162 témoins et de 246 femmes dont l'anatomo-pathologiste centralisateur a considéré qu'elles étaient porteuses d'un cancer du sein. Quinze cas $(6 \%)$ et 381 témoins $(9,2 \%)$ avaient précédemment utilisé du DMPA; on a estimé que le risque relatif de cancer du sein pour les femmes ayant pris du DMPA à une période quelconque de leur vie était de 0,7 (intervalle de confiance à $95 \%: 0,4-1,2$ ) une fois éliminée l'influence globale de l'âge, du centre, de l'âge à la naissance du premier enfant et de la nulliparité. Une correction effectuée pour d'autres facteurs de risque de cancer du sein n'a pas modifié cette estimation de façon appréciable.

Le risque avait sa plus faible valeur chez les femmes ayant utilisé du DMPA pendant au moins 3 ans (risque relatif $=0,5$, intervalle de confiance à $95 \%: 0,2-1,5)$ bien qu'on n'ait pas pu mettre en évidence de nette tendance à la baisse avec la durée d'utilisation. La diminution apparente du risque se limitait aux femmes qui avaient pris du DMPA pour la première fois après l'âge de 30 ans.

Le nombre de cas rassemblés dans cette étude est encore insuffisant pour qu'on ait une estimation stable du risque relatif chez les utilisatrices de DMPA à une période quel- 
conque de leur vie et pour qu'on puisse procéder à des analyses plus fines, de puissance statistique convenable: par conséquent, la collecte des données se poursuit dans tous les centres dont on a parlé dans ce rapport. Cependant, il est certain que ces résultats préliminaires ne témoignent nullement d'une augmentation du risque de cancer du sein chez les femmes par le DMPA, mais donneraient plutôt à penser qu'il a un rôle protecteur.

\section{REFERENCES}

1. Facts about injectable contraceptives: Memorandum from a WHO meeting. Bulletin of the World Health Organization, 60: 199-210 (1982).

2. Fraser, I. S. \& WeisberG, E. A comprehensive review of injectable contraception with special emphasis on depot-medroxyprogesterone acetate. Medical journal of Australia, 1 (Suppl.): 1-9 (1981).

3. Rosenfield, A. et Al. The Food and Drug Administration and medroxyprogesterone acetate. What are the issues? Journal of the American Medical Association, 249: 2922-2928 (1983).

4. Greenspan, A. R. et al. The association of depotmedroxyprogesterone acetate and breast cancer. Contraception, 21: 563-569 (1980).

5. LIANG, A. P. ET AL. Risk of breast, uterine corpus, and ovarian cancer in women receiving medroxyprogesterone injections. Journal of the American Medical Association, 249: 2909-2912 (1983).
6. WHO Collaborative Study of Neoplasia and Steroid Contraceptives. Invasive cervical cancer and combined oral contraceptives. British medical journal, 290: 961-965 (1985).

7. SoBIn, L. H. ET AL., ed. A coded compendium of the International Histological Classification of Tumours. Geneva, World Health Organization, 1978.

8. BRESLOW, N. E. \& DAY, N. E. Statistical methods in cancer research. Vol. 1. The analysis of case-control studies. Lyon, International Agency for Research on Cancer, 1980 (IARC Scientific Publication, No. 32).

9. Gambrell, R. D. JR. ET AL. Decreased incidence of breast cancer in postmenopausal estrogen-progestogen users. Obstetrics and gynecology, 62: 435-443 (1983).

10. Nachtigall, L. E. ET AL. Estrogen replacement therapy. II: A prospective study on the relationship to carcinoma and cardiovascular and metabolic problems. Obstetrics and gynecology, 54: 74-79 (1979).

\section{PARTICIPATING CENTRES AND INVESTIGATORS}

The data collection centres and investigators were as follows:

\section{University of Nairobi, Nairobi Centre for Research in Reproduction, Nairobi, Kenya}
J. K. G. Mati, ${ }^{a}$ Patrick R. Kenya, ${ }^{b}$ Alfred Kungu," D. Gatei."

\section{Mexico General Hospital, Mexico City, Mexico}

Hector Rodriguez Cuevas, ${ }^{\prime}$ Socorro Benavides Salazar, ${ }^{b}$ Jorges Albores Saavedra, ${ }^{c}$ Patricia Ontiveros. ${ }^{c}$

\footnotetext{
" Principal investigator.

"Co-investigator.

c Pathologist.
}

Chiang Mai University, Faculty of Medicine, Chiang Mai, Thailand

Suporn Silpisornkosol, ${ }^{a}$ Tieng Pardthaisong, ${ }^{b}$ Nimit Martin, ${ }^{b}$ Choti Theetranont. ${ }^{c}$

Chulalongkorn University, Faculty of Medicine, Department of Obstetrics and Gynaecology, WHO Collaborating Centre for Research in Human Reproduction, Bangkok, Thailand

Banpot Boonsiri, ${ }^{a}$ Pramuan Virutamasen, ${ }^{b}$ Chansuda Wongsrichanalai, ${ }^{b}$ Prasarn Jimakorn. ${ }^{c}$

Mahidol University, Faculty of Medicine, Siriraj Hospital, Department of Obstetrics and Gynaecology, Family Planning Research Unit, Bangkok, Thailand

Suporn Koetsawang," Daungdao Rachawat, Nivat Chantarakul." 
Coordinating Centre

Fred Hutchinson Cancer Research Center, Division of Public Health Sciences, Seattle, $W A, U S A$

David B. Thomas (Study Coordinator), Diane Roseman (Epidemiologist), Anne Whitehead (Statistician), Liza Noonan (Statistician).

\section{Reference pathologist}

Helge Stalsberg, University of Tromsö, Institute of Medical Biology, Tromsö, Norway.

\section{World Health Organization}

Susan Holck, Special Programme of Research, Development and Research Training in Human Reproduction, World Health Organization, Geneva, Switzerland. 